\title{
Emergence of a Cue Strategy Preference on the Water Maze Task in Aged C57B6 × S]L F1 Hybrid Mice
}

\author{
Michelle M. Nicolle, ${ }^{1,3,4}$ Sonya Prescott, ${ }^{1}$ and Jennifer L. Bizon ${ }^{2,3}$ \\ ${ }^{1}$ Department of Molecular Neuroscience, Mayo Graduate School, Mayo Clinic, Jacksonville, Florida 32224, USA; ${ }^{2}$ Department of \\ Psychology, Texas A\&M University, College Station, Texas 77843-4235, USA
}

\begin{abstract}
The effects of age on cue learning, spatial reference memory, and strategy preference were assessed in B6 $\times$ SJL F1 mice by using the Morris water maze. This mouse strain is of particular interest because it is the background strain for a common transgenic model of Alzheimer's disease, the Tg2576 mouse, which develops plaques and other neurobiological markers of pathology beginning at $8 \mathrm{mo}$ and increasing in severity with advanced age. In the current study, 12- and 23-mo-old C57B6 $\times$ SJL F1 mice were serially trained in cue and place versions of the Morris water maze task. At the completion of training, mice received a strategy probe test in which place (hidden) and cue (visible) strategies were in competition. Cue and spatial learning ability was maintained between 12 and 23 mo of age; however, on the strategy preference probe test, the 23-mo-old mice exhibited a significant bias toward the selection of a cue strategy. There was no relationship between strategy preference in the probe test and spatial learning ability, but the 23-mo-old mice did exhibit a strong trend toward shorter latencies during visible platform training, possibly reflecting the enhanced function of striatal-based neural systems in aging. These data demonstrate that 23-mo-old C57B6 $\times$ SJL F1 mice are capable of effective place learning, but if a place strategy is pitted against the use of a cue strategy, the use of a cue strategy predominates in the aged mice. The strategy preference observed here may reflect an emergence of differential processing in underlying brain circuitry with age in the B6 $\times$ SJL F1 mouse strain.
\end{abstract}

Substantial literature regarding the disparate behavioral phenotypes of background mouse strains used for targeted gene mutations highlights the need for careful behavioral characterization in the host strain prior to interpreting the effects of mutations (Crawley et al. 1997; Wahlsten et al. 2003). In addition, when the expression of the gene mutation is age-dependent, understanding the effects of age on the behavior of interest in that particular strain is crucial; the neurobiology of aging can vary across strains, as different strains have different life spans and susceptibility to diseases of aging (Wahlsten et al. 2003). The present study was designed to assess the effects of normal aging on cue learning, spatial learning, and strategy preference in the mouse hybrid strain C57B $6 \times$ SJL F1. This strain has been used as the background strain for a common transgenic model of Alzheimer's disease, the Tg2576 mouse (see Hsiao et al. 1996; Westerman et al. 2002). Because the mutant mouse begins to show pathology at 8 mo of age that becomes more pronounced over time (Kawarabayashi et al. 2001; Westerman et al. 2002), the current study focused on spatial behaviors in the background strain at middle (12 mo) and advanced (23 mo) ages.

In addition to traditional water maze measures (i.e., cue learning and spatial reference learning), strategy preference was assessed in the current study by evaluating strategy choice (cue or spatial) after serial acquisition of the cue learning and spatial reference memory task. Evidence in humans and rats indicates that different neural systems are recruited to solve navigational tasks depending upon the type of learning involved (McDonald

${ }^{3}$ These authors contributed equally to this work.
${ }^{4}$ Corresponding author.

E-MAIL nicolle.michelle@mayo.edu; FAX (904) 953-7117.

Article and publication are at http://www.learnmem.org/cgi/doi/10.1101/ Im.64803. and White 1994; Packard and McGaugh 1996; Oliveira et al. 1997; Devan and White 1999; Packard 1999; Colombo et al. 2003; Hartley et al. 2003). A spatial/place strategy, which involves the flexible use of spatial cues, is dependent upon intact hippocampal circuitry. Conversely, a response/cue strategy, or the formation of associations between discreet cues and behavioral responses, is dependent upon intact striatal circuitry.

Although the striatal and hippocampal memory systems might be sufficiently preserved in aging to support the acquisition of new learning, there is evidence to indicate that the access to information from these discrete memory systems might differ with age and genetic predisposition. Indeed, genetic variability in learning strategy has been demonstrated between C57B6 and DBA/2 mice. These strains of mice naturally differ with regards to their preference for place or response learning, and their behavioral preferences are reflected in distinct neural system activation measured by FOS expression (Passino et al. 2002). In addition, aged rats show a reduction in the use of a place strategy and an increase in the use of a response strategy to solve a T-maze task (Barnes et al. 1980). This change in strategy preference may reflect an age-related change in the ability to access information from either the hippocampal or striatal-based learning systems.

The results from the current study demonstrate that cue and spatial memory was maintained between 12 and 23 mo of age in C57B6 $\times$ SJL F1 mice. Interestingly, however, the 23-mo-old mice all used a cue strategy on the strategy preference probe test, whereas a more even distribution between place and cue strategies was observed in the younger 12-mo-old mice. These data indicate a subtle alteration in the behavior of aged C57B6 $\times \mathrm{SJL}$ F1 mice, which might reflect age-related differences in underlying brain circuitry. Moreover, these findings indicate that strategy preference may be an informative behavioral assessment in transgenic mouse models of aging. 


\section{RESULTS}

\section{Cue and Place Acquisition}

Latencies to escape on the visible (left panel) and hidden (right panel) platform trials are shown in Figure 1. Both age groups improved during the course of training on both visible and hidden trials. Two-factor ANOVAs (age $\times$ trial block) revealed significantly shorter latencies over training for both visible $[\mathrm{F}(1,3)=085.95, \quad P<0.0001]$ and hidden $[\mathrm{F}(1,9)=013.84$, $P<0.0001]$ trials. There was no significant main effect of age for visible $[\mathrm{F}(1,29)=3.81, P=0.06]$ or hidden $[\mathrm{F}(1,29)=2.85$, $P=0.10]$ trials; however, note the trend for the 23-mo-old mice to find the visible platform more quickly than do the 12-mo-old mice. Search error was also evaluated for hidden platform trials (data not shown). In agreement with the latency data, a twofactor ANOVA (age $\times$ trial block) of search error data revealed that both 12-and 23-mo-old mice improved during training $[\mathrm{F}(1,9)=18.92, P<0.0001]$, but that there was no significant effect of age $[\mathrm{F}(1,29)=1.67, P=0.21]$.

\section{Spatial Memory}

Spatial bias was assessed three times during the course of training with the use of a 30-sec probe trial. Mice from both age groups developed a spatial bias by the second probe trial, spending $\sim 40 \%$ of their time in the training quadrant (Fig. 2).

Swim speed was averaged over the three probe trials that occurred during place learning. A one-factor ANOVA (age) indicated no significant difference in swim speed between 12- and 23-mo-old mice $[\mathrm{F}(1,29)=2.09, P<0.16]$. The swim speeds were as follows $( \pm$ SEM): $12 \mathrm{mo}, 17.91 \pm 1.10 ; 23 \mathrm{mo}, 15.30 \pm 1.47$ $\mathrm{cm} / \mathrm{sec}$.

\section{Strategy Probe Test}

After acquisition of both cue and place learning, the mice received two strategy probe trials in which a visible platform was placed in the quadrant opposite the original hidden platform training quadrant. The strategies of the mice on these competition trials were classified as either place or cue, based on the swim path for those trials. As shown in Figure 3, mice were scored as exhibiting a "place strategy" if they crossed the original hidden platform annulus prior to escaping to the visible platform. Mice were scored as exhibiting a "cue strategy" if they swam to the visible platform without first visiting the prior hidden platform location. Data from the first strategy probe trial are shown in Table 1. Interestingly, although 23-mo-old mice were not impaired on acquisition of the spatial learning task or in the development of a spatial bias, all of the 23-mo-old mice used a cue strategy on the strategy probe test. In contrast, 12-mo-old mice
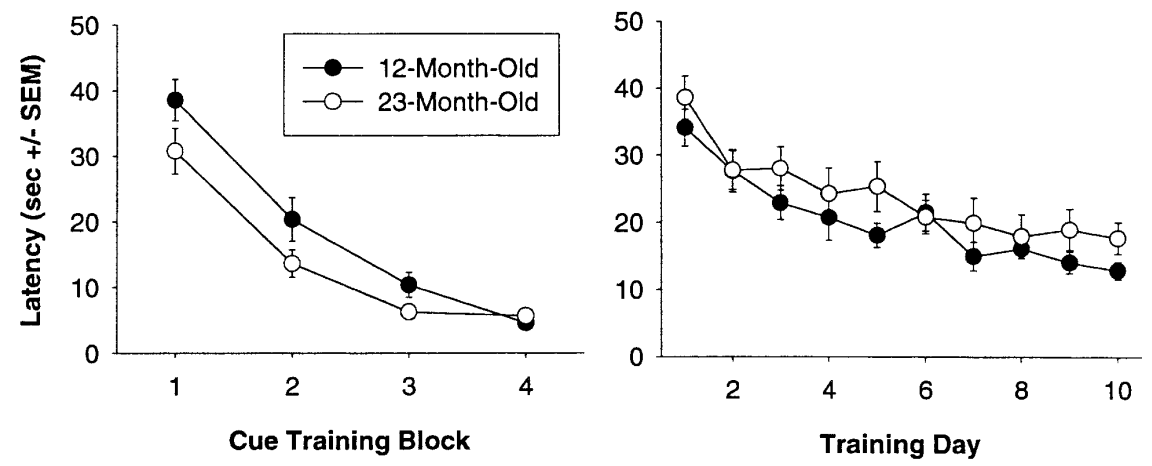

Figure 1 (Left) The escape latency to a visible platform. There is no significant difference in cue training between age groups $(P=0.06)$. (Right) No significant difference $(P=0.10)$ in the latency of the same mice to escape to the hidden platform.
Table 1. Number of Mice Using Place or Cue Strategies on First Strategy Probe Test

\begin{tabular}{lcc}
\hline & 12-mo-old & 23-mo-old \\
\hline $\begin{array}{c}\text { Place strategy } \\
\text { (hidden platform location) }\end{array}$ & 7 & 0 \\
$\begin{array}{c}\text { Cue strategy } \\
\text { (visible platform location) }\end{array}$ & 10 & 14 \\
\hline
\end{tabular}

were more evenly divided between the use of place and cue strategies (Table 1). The cue bias observed in the 23-mo-old mice was significant using a $\chi^{2}$ analysis $\left(\chi^{2}=7.45, P<0.01\right)$. On the second competition trial, all of the 23 -mo-old mice and all but two of the 12-mo-old mice adopted the more effective cue strategy (Aged: $\mathrm{n}=14$ cue, $\mathrm{n}=0$ place; Adult: $\mathrm{n}=15$ cue, $\mathrm{n}=2$ place). There was no significant difference in responses between 12- and 23-mo-old mice on the second trial $\left(\chi^{2}=2.53, P=0.11\right)$.

\section{Sex Differences}

Sex differences were evaluated on all measures (visible and hidden platform acquisition, spatial memory bias, and the strategy probe test). These analyses revealed that 12 -mo-old males spent more time in the training quadrant during the first probe trial compared with that of 12-mo-old females, reflecting a faster development of spatial bias [age $\times$ sex interaction, $\mathrm{F}(1,1)=4.01$, $P=0.055$; followed post hoc by a 1-factor ANOVA ( $\times$ sex), $\mathrm{F}(1,15)=7.68, P=0.01$ for probe trial 1 ; females $=25.78 \pm 1.82$ and males $=38.46 \pm 4.41 \%$ time in training quadrant \pm SEM] . No other significant effects of sex were found.

\section{DISCUSSION}

The current data demonstrate that although 23-mo-old C56B6 $\times$ SJL F1 hybrids did not exhibit impaired place or cue learning compared with that of 12-mo-old mice, the older mice did exhibit a strong and significant "cue bias" when place and cue strategies were placed in opposition. In agreement with previous studies using adult rats (McDonald and White 1994; Devan and White 1999), 12-mo-old mice were divided by the strategies they used on the first strategy probe test, which represents the most unbiased measure of strategy. Approximately half of the 12-mo-old mice visited the original place training platform location before escaping to the visible platform located in the opposite quadrant, whereas the other half swam directly to the new visible platform location. In contrast, all of the 23-mo-old mice swam to the visible platform without visiting the original platform location. Not surprisingly, as in adult rats, most mice in the current study adapted to the new visible platform location by the second strategy probe trial (Devan and White 1999; Bizon et al. 2003).

The use of such strategy probe tests in water maze and on other tasks (e.g., T-maze) can be informative with respect to the basis of performance for the subjects in venues where multiple strategies can be used. Several factors have been shown to contribute to the choice of strategy in such settings. For example, the amount of training can influence the selection of strategy in the Tmaze, with place strategies predominating earlier in training but response strategies prevailing on later trials (Restle 1957; Packard and McGaugh 1996; Packard 1999). Perhaps most interestingly, place and cue strat- 
Probe 1

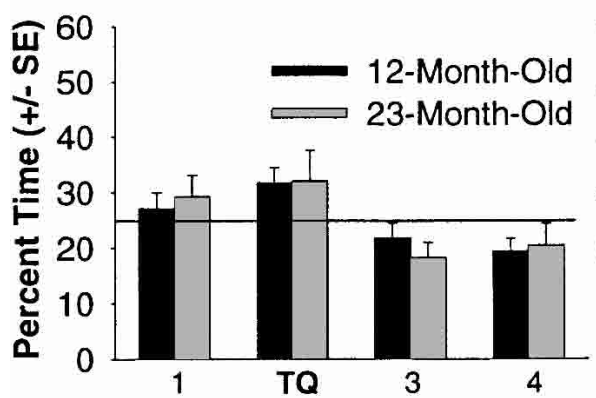

Probe 2

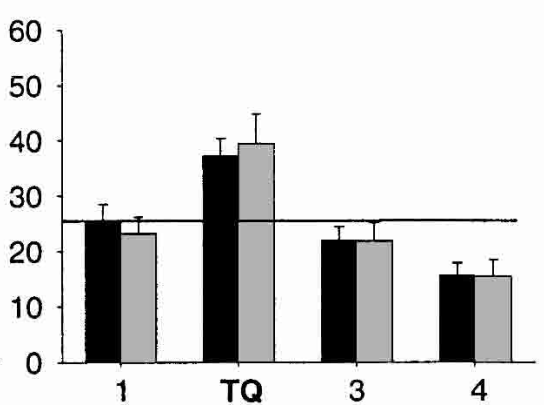

Probe 3

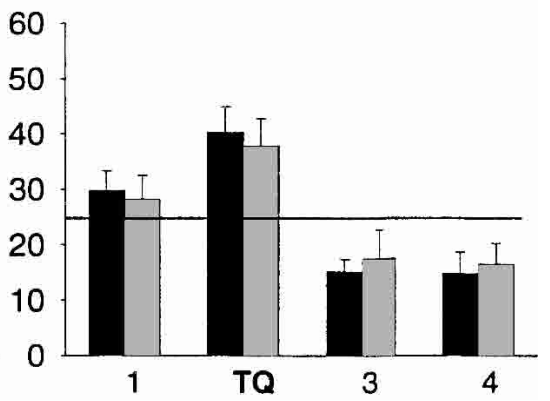

Figure 2 The percentage of time in the four water maze quadrants over three probe trials. The probe trials occurred on training days 3 , 7, and 10. TQ indicates the quadrant that contained the escape platform. The numbers 1, 3, and 4 indicate the other quadrants of the maze. The horizontal line marks chance performance. The data show that both age groups developed a spatial bias for the training quadrant.

egies have been dissociated by manipulations of different neural systems, and strategy choice has been shown to reflect the functional status of the underlying circuits (Packard and McGaugh 1996; Oliveira et al. 1997; Packard 1999; Colombo et al. 2003). Specifically, on the water maze task, hippocampal inactivation disrupts spatial learning and promotes the use of a cue strategy, whereas dorsal striatal inactivation disrupts cue learning and promotes the use of a place strategy (McDonald and White 1994). With parallel brain systems underlying place and cue strategies, it is possible that the cue bias in the aged mice reflects a shift of informational processing away from the hippocampal formation and toward the dorsal striatal system. Such a shift is supported by the strong trend toward the aged mice locating the visible platform more quickly during training than do the 12-mo-old mice $(\mathrm{F}=3.81, P=0.06)$. These data are consistent with previous work demonstrating a cue strategy preference in aged rodents. Aged rats shift to a response strategy in the T-maze more quickly than do young rats (Barnes et al. 1980), and aged C57BL/B6 mice preferentially use a serial search strategy over a spatial search strategy in the Barnes circular maze (Bach et al. 1999). Neurobiological data are also consistent with this interpretation. In aged rats, striatal N-methyl-D-aspartate (NMDA) receptor binding is inversely correlated with spatial learning performance, with highest levels of striatal NMDA receptor binding found in rats with the greatest degree of hippocampal impairment (Nicolle et al. 1996).

Importantly, in the current study, the 23-mo-old mice were not impaired relative to the 12-mo-old mice on the place training protocol. A weak trend toward impairment in the aged mice $(P=0.1)$ was observed with the latency data obtained from the place training protocol, but analysis using search error, a proximity measure that is highly sensitive to age-related impairment (Gallagher et al. 1993), did not substantiate the trend toward longer escape latencies in the old mice. Moreover, probe trial performance, which is generally considered a more accurate measure of spatial learning, was not affected by age in the current study. Other work with this hybrid strain reports no spatial learning deficit in the water maze between 4 and 18 mo (Westerman et al. 2002). In contrast to the current study, Westerman et al. (2002) did report a slight probe trial deficit in aged C57B6 $\times$ SJL F1 mice, which ranged in age from 20 to 25 mo. This slower development of a spatial bias was not observed in our group of 23-mo-old mice, perhaps due to our more restricted age range and/or different exclusion criteria (see Materials and Methods). It will be of interest in the future to assess strategy choice in young C57B6 $\times$ SJL F1 mice in order to determine if the evenly distributed strategy choice observed at middle age is reflective of young performance or, alternatively, if young mice preferentially use a place strategy, indicating a progressive shift to cue strategy over the lifespan.

The data from the present study demonstrate that aged mice show a preference for using a cue strategy over a place strategy when both types of previously learned information (i.e., spatial or cued) are available to solve the task. Unlike some previous experimental designs, in which place and cue strategies are made redundant during training (see Sutherland and Rudy 1988; McDonald and White 1994), the serial presentation of cue and place learning makes it possible to independently assess age-related impairments on the two different types of learning. From the current data, it is clear that the hippocampal system in aged C57B6 $\times$ SJL F1 mice is sufficiently preserved to support place learning well into advanced age. The ability of the aged mice to acquire the spatial task clearly indicates that their cue bias during the strategy probe trial cannot simply be attributed to gross sensory, motor, or motivational deficits. It also is not likely that the initial cue learning assessment directly interfered with the encoding of spatial information during place learning. Instead, the choice of a cue strategy by the aged mice during the strategy probe trial more likely reflects a difference in the ability to access the two types of learned information (i.e., spatial and cued). This reduction in the ability to access the previously learned spatial information may reflect the presence of a subtle age-related cog-
Place Responders

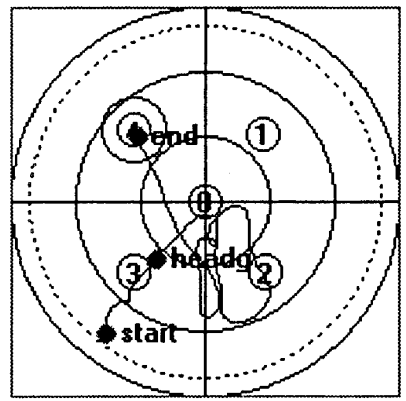

Subject 2 Trial 1

Original Escape Platform $=2$

Competition Escape Platform $=4$
Cue Responders

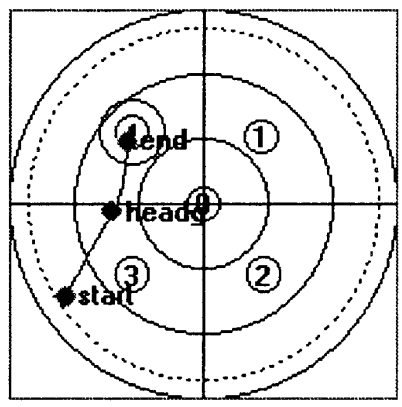

Subject 9 Trial 1

Original Escape Platform $=2$

Competition Escape Platform $=4$
Figure 3 Representative swim paths of "place" and "cue" responders. The "place responder" crosses the annulus of the hidden escape platform prior to going to the visible platform. The "cue responder" goes directly to the visible platform. Quadrant 2 was the previous location of hidden platform during the spatial learning phase of training, and quadrant 4 is the location of the visible platform during the strategy probe test. 
nitive deficit in the hippocampal system. Indeed, age-related hippocampal impairment, as measured by spatial learning, is not always profound (see Gallagher et al. 1993), and it is possible that the strategy probe test is more sensitive to modest hippocampal impairment than is the place training protocol used here. Reportedly, even aged rats that are impaired in their acquisition of place learning can eventually reach young performance levels with prolonged training (Rapp et al. 1987).

Another possibility worthy of consideration is that the age difference on the strategy probe trial reflects altered processing in a third brain system that is critically involved in the recall of the learned information supported by other structures. For example, the prefrontal cortex has been implicated in the choice of strategy on tasks similar to those used in the current study, and agerelated impairments have been linked to this region (Ragozzino et al. 1999a,b; Barense et al. 2002). It will be an informative avenue of future study to investigate whether the age-related strategy differences described here are reflected in other behavioral venues and/or are predictive of the later emergence of more pronounced learning deficits. Within this context, strategy selection may be a valuable and informative behavioral assessment in rodent models of aging.

\section{MATERIALS AND METHODS}

\section{Subjects}

The subjects were male and female C57B6 $\times$ SJL F1 hybrid mice, bred in the Mayo Clinic Jacksonville vivarium. A difficulty in assessing cognition in these animals is that the SJL strain is known to carry the $r d$ mutation, which results in retinal degeneration and blindness (Wahlsten et al. 2003). To avoid confounds due to visual impairment, any mouse that failed cue training ( $>2$ SD from the group mean) was eliminated from further testing. This came to $3 \%$ of our mice (collapsed across age). In addition, only mice with pigmented eyes were assessed in the water maze. Rodents without eye pigmentation (red eyes) are susceptible to problems in visual acquity (Prusky et al. 2002), especially with advancing age. Based on data from our colony, $\sim 30 \%$ of C57B6 $\times$ SJL F1 mice are nonpigmented. The final number, and age, of subjects that underwent behavioral testing was 17 female mice $(\mathrm{n}=9,12$-mo-olds and $\mathrm{n}=823$-mo-olds) and 14 male mice ( $\mathrm{n}=8$ 12-mo-olds and $\mathrm{n}=6$ 23-mo-olds). All mice were grouphoused in the Mayo Clinic Research vivarium with ad lib access to food and water. Mice were group housed in a barrier facility until 1 wk prior to water maze testing, when they were individually housed. Mice were handled for $\sim 2 \mathrm{~min}$ for $5 \mathrm{~d}$ prior to cue training.

\section{Water Maze Protocol}

The water maze consists of a circular tank (4-ft diameter) with a removable escape platform centered in one of the four maze quadrants. Black curtains with white patterns surround the maze, providing distal spatial cues. During testing, the tank is filled with $25^{\circ} \mathrm{C}$ water clouded by nontoxic white paint. The training sequence consisted of $2 \mathrm{~d}$ of cue (visible platform) training (six trials per day) followed immediately by $10 \mathrm{~d}$ of place (hidden platform) training (four trials per day). Twenty-four hours after the completion of training, the strategy probe test was performed as described below.

\section{Cue Training}

A visible black platform extended $2 \mathrm{~cm}$ from the water surface and was moved to different locations in the pool between trials. One of the platform locations was centered in the middle of the tank to encourage a randomized search pattern. Each mouse was given $60 \mathrm{sec}$ to reach the platform and was allowed to remain on it briefly. Trials were separated by a $\sim 10$-min intertrial interval, during which time the mouse was placed into a holding cage.
The start quadrants were varied for each trial. Cue training took place for the first $2 \mathrm{~d}$ of training with 6 trials per day.

\section{Place Training}

For hidden platform training trials, the top of the escape platform was submerged $1 \mathrm{~cm}$ below the water surface, and the platform location remained stationary during the course of training. The position of entry was varied at each trial. The mouse was placed in the water at the perimeter of the pool and was allowed $60 \mathrm{sec}$ to locate the escape platform. If the mouse did not escape in the allocated time, it was led to the platform with the use of a net scoop. There were four training trials per day for $10 \mathrm{~d}$. After finding the escape platform, mice remained on it for $30 \mathrm{sec}$ and then were placed into a holding cage for a $\sim 10$-min intertrial interval. The first trial of training days 4,7 , and 10 consisted of a 30 -sec probe trial that served to assess the development of a spatially localized search for the escape platform. During a probe trial, the platform was retracted, and the mouse was given $30 \mathrm{sec}$ to search. At the end of $30 \mathrm{sec}$, the platform was raised, and the mouse was given an additional 30 sec to find the escape platform. This procedure helps to minimize any extinction that could occur when the platform is retracted. On the last day, four training trials followed the last probe trial.

\section{Strategy Probe Test}

Strategy preference was assessed $24 \mathrm{~h}$ after the last day of place training. A visible platform was placed in the quadrant opposite the training quadrant where the hidden platform was previously located. The mice were given two 60-sec strategy probe trials. Start locations were on either side of the tank, equidistant from the visible cue platform and the prior hidden platform location. A "place strategy" was recorded if the mouse crossed the annulus of the prior hidden platform location before escaping to the visible platform. The annulus was defined as a $5-\mathrm{cm}$ perimeter around the prior hidden escape platform location. A "cue strategy" was recorded if the mouse did not cross the prior hidden platform annulus before swimming to the visible platform. Data was scored by observation of recorded swim paths by the HVS Imaging program.

\section{Data Analysis}

Data were analyzed by using a video tracking system and software developed by Richard Baker, HVS Image Analyzing (Hampton, UK.). The latency and search error over the course of training trials were analyzed by a two-factor repeated-measure ANOVA (age $\times$ trial block) to determine the rate of acquisition of the spatial learning task. To determine if there were sex differences, females and males were compared by using a three-factor repeated-measure ANOVA (age $\times$ sex $\times$ trial block). Strategy selection was assessed by using a $\chi^{2}$ analysis. In all cases, $P<0.05$ was considered significant.

\section{ACKNOWLEDGMENTS}

We thank Steven Younkin, M.D., Ph.D., for the generous donation of the C57B6 $\times$ SJL F1 mice. This work was supported by the Mayo Foundation.

The publication costs of this article were defrayed in part by payment of page charges. This article must therefore be hereby marked "advertisement" in accordance with 18 USC section 1734 solely to indicate this fact.

\section{REFERENCES}

Bach, M.E., Barad, M., Son, H., Zhuo, M., Lu, Y.F., Shih, R., Mansuy, I. Hawkins, R.D., and Kandel, E.R. 1999. Age-related defects in spatial memory are correlated with defects in the late phase of hippocampal long-term potentiation in vitro and are attenuated by drugs that enhance the cAMP signaling pathway. Proc. Natl. Acad. Sci. 96: $5280-5285$.

Barense, M.D., Fox, M.T., and Baxter, M.G. 2002. Aged rats are impaired on an attentional set-shifting task sensitive to medial frontal cortex damage in young rats. Learn. Mem. 9: 191-201.

Barnes, C., Nadel, L., and Honig, W. 1980. Spatial memory deficit in 
senescent rats. Can. J. Psychol. 34: 29-39.

Bizon, J.L., Han, J.-S., Hudon, C., and Gallagher, M. 2003. Effects of hippocampal cholinergic deafferentation on learning strategy selection in a visible platform version of the water maze. Hippocampus 13: 676-684.

Colombo, P.J., Brightwell, J.J., and Countryman, R.A. 2003. Cognitive strategy-specific increases in phosphorylated cAMP response element-binding protein and c-Fos in the hippocampus and dorsal striatum. J. Neurosci. 23: 3547-3554.

Crawley, J.N., Belknap, J.K., Collins, A., Crabbe, J.C., Frankel, W. Henderson, N., Hitzemann, R.J., Maxson, S.C., Miner, L.L., Silva, A.J., et al. 1997. Behavioral phenotypes of inbred mouse strains: Implications and recommendations for molecular studies. Psychopharmacology (Berl) 132: 107-124.

Devan, B.D. and White, N.M. 1999. Parallel information processing in the dorsal striatum: Relation to hippocampal function. J. Neurosci. 19: 2789-2798.

Gallagher, M., Burwell, R., and Burchinal, M. 1993. Severity of spatial learning impairment in aging: Development of a learning index for performance in the Morris water maze. Behav. Neurosci. 107: 618-626.

Hartley, T., Maguire, E.A., Spiers, H.J. and Burgess, N. 2003. The well-worn route and the path less traveled: distinct neural bases of route following and wayfinding in humans. Neuron 37: 877-888.

Hsiao, K., Chapman, P., Nilsen, S., Eckman, C., Harigaya, Y., Younkin, S., Yang, F., and Cole, G. 1996. Correlative memory deficits, A $\beta$ elevation, and amyloid plaques in transgenic mice. Science 274: 99-102.

Kawarabayashi, T., Younkin, L., Saido, T., Shoji, M., Ashe, K., and Younkin, S. 2001. Age-dependent changes in brain, CSF, and plasma amyloid $(\beta)$ protein in the Tg2576 transgenic mouse model of Alzheimer's disease. J. Neurosci. 21: 372-381.

McDonald, R.J. and White, N.M. 1994. Parallel information processing in the water maze: Evidence for independent memory systems involving dorsal striatum and hippocampus. Behav. Neural Biol. 61: $260-270$.

Nicolle, M.M., Bizon, J.L., and Gallagher, M. 1996. In vitro autoradiography of ionotropic glutamate receptors in hippocampus and striatum of aged Long-Evans rats: Relationship to spatial learning. Neuroscience 74: 741-756.

Oliveira, M.G., Bueno, O.F., Pomarico, A.C., and Gugliano, E.B. 1997. Strategies used by hippocampal- and caudate-putamen-lesioned rats in a learning task. Neurobiol. Learn. Mem. 68: 32-41.

Packard, M.G. 1999. Glutamate infused posttraining into the hippocampus or caudate-putamen differentially strengthens place and response learning. Proc. Natl. Acad. Sci. 96: 12881-12886.

Packard, M.G. and McGaugh, J.L. 1996. Inactivation of hippocampus or caudate nucleus with lidocaine differentially affects expression of place and response learning. Neurobiol. Learn. Mem. 65: 65-72.

Passino, E., Middei, S., Restivo, L., Bertaina-Anglade, V., and Ammassari-Teule, M. 2002. Genetic approach to variability of memory systems: Analysis of place vs. response learning and fos-related expression in hippocampal and striatal areas of C57BL/6 and DBA/2 mice. Hippocampus 12: 63-75.

Prusky, G.T., Harker, K.T., Douglas, R.M., and Whishaw, I.Q. 2002. Variation in visual acuity within pigmented, and between pigmented and albino rat strains. Behav. Brain Res. 136: 339-348.

Ragozzino, M.E., Detrick, S., and Kesner, R.P. 1999a. Involvement of the prelimbic-infralimbic areas of the rodent prefrontal cortex in behavioral flexibility for place and response learning. J. Neurosci. 19: $4585-4594$

Ragozzino, M.E., Wilcox, C., Raso, M., and Kesner, R.P. 1999 b. Involvement of rodent prefrontal cortex subregions in strategy switching. Behav. Neurosci. 113: 32-41.

Rapp, P.R., Rosenberg, R.A., and Gallagher, M. 1987. An evaluation of spatial information processing in aged rats. Behav. Neurosci. 101: $3-12$.

Restle, F. 1957. Discrimination of the cues in mazes: A resolution of the "place vs. response" question. Psychol. Rev. 64: 217-228.

Sutherland, R.J. and Rudy, J.W. 1988. Place learning in the Morris place navigation task is impaired by damage to the hippocampal formation even if the temporal demands are reduced. Psychobiology 16: $157-163$.

Wahlsten, D., Rustay, N.R., Metten, P., and Crabbe, J.C. 2003. In search of a better mouse test. Trends Neurosci. 26: 132-136.

Westerman, M.A., Cooper-Blacketer, D., Mariash, A., Kotilinek, L., Kawarabayashi, T., Younkin, L.H., Carlson, G.A., Younkin, S.G., and Ashe, K.H. 2002. The relationship between $A \beta$ and memory in the Tg2576 mouse model of Alzheimer's disease. J. Neurosci. 22: $1858-1867$

Received June 18, 2003; accepted in revised form September 25, 2003.

\section{Learning \& Memory}




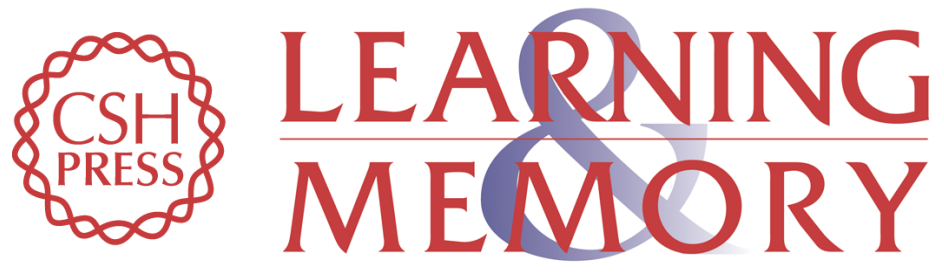

\section{Emergence of a Cue Strategy Preference on the Water Maze Task in Aged C57B6 × SJL F1 Hybrid Mice}

Michelle M. Nicolle, Sonya Prescott and Jennifer L. Bizon

Learn. Mem. 2003, 10:

Access the most recent version at doi:10.1101/lm.64803

References This article cites 25 articles, 9 of which can be accessed free at:

http://learnmem.cshlp.org/content/10/6/520.full.html\#ref-list-1

License

Email Alerting Receive free email alerts when new articles cite this article - sign up in the box at the Service top right corner of the article or click here. 